\title{
LA MISIÓN SECRETA DE D. RICARDO WALL EN LONDRES (1747-1748)
}

\author{
Diego Téllez Alarcia*
}

\section{El contexto internacional: la Guerra de Sucesión Austríaca}

Si algo caracterizó el ámbito de las relaciones internacionales, durante la primera mitad del siglo XVIII, no fue precisamente la paz que el "equilibrio europeo" basado en el "sistema heredado de Utrecht" buscaba. Tal equilibrio resultó, en el mejor de los casos, inestable, ya que las guerras se encadenaron unas a otras sin solución de continuidad durante toda la centuria y sin ni siquiera una cohesión uniforme en las alianzas, que se mostraron tan perecederas como la paz. No obstante, en aras de dicho equilibrio, se prodigaron las intervenciones extranjeras en los conflictos sucesorios de todo el continente, auténtico elemento definidor de la esencia del contexto internacional que fue dominante en este periodo.

España participó, de la mano de Felipe $V$ e Isabel Farnesio, en la mayor parte de estos escenarios bélicos, haciendo alarde de un ansia revisionista que difícilmente podía esconder el resentimiento por las duras condiciones de los tratados de 1713 y 1714, así como una meditada vocación mediterránea en unos monarcas que deseaban heredar la influencia en Italia que habían disfrutado sus antecesores en el trono, los Austrias, y que ambicionaban proporcionar a su dilatada prole asentamientos dignos de su regia estirpe.

El estallido de la Guerra de Sucesión Austríaca (1740-1748), la tercera de estas características en menos de 50 años, ofreció el pretexto perfecto para una

* Becario FPI de la Universidad de La Rioja, realiza su tesis doctoral bajo la dirección del catedrático de Historia Moderna D. José Luis Gómez Urdáñez. Este trabajo se incluye en el proyecto de investigación El Ensenadismo Riojano: el grupo de poder del marqués de la Ensenada y la oposición antiensenadista, financiado por el I Plan Riojano de I+D, del Gobierno de La Rioja. 
tentativa semejante: la de alcanzar ese "establecimiento" para el infante D. Felipe, segundo hijo de los monarcas, en la Lombardía -el primero, Carlos, ya era rey de Nápoles tras las campañas de 1734-1735-. El 20 de octubre de 1740 había fallecido el emperador Carlos VI sin descendencia masculina. La sucesión al trono, que recaía teóricamente en su hija, María Teresa gracias a la que era reciente aprobación de la Pragmática Sanción, no sería aceptada por algunas potencias, que veían la oportunidad perfecta para disgregar al Imperio. Tras unos titubeos iniciales, Francia, la principal interesada por su tradicional enfrentamiento con los Austrias, se declaró partidaria de la elección de Carlos VII, perteneciente a una de las ramas colaterales de la familia. Tras permitir a Felipe $\mathrm{V}$ el paso de un cuerpo de ejército por su territorio con rumbo a Italia, se suscribiría entre ambas coronas el Segundo Pacto de Familia (Fontainebleau, 28 de octubre de 1743), implicándose directamente en el conflicto. El panorama de la guerra se completaba del siguiente modo: Inglaterra y Cerdeña se alineaban frente a la coalición borbónica -de hecho los británicos ya estaban en guerra con España desde 1739 (la Guerra de la Oreja de Jenkins), un conflicto que tuvo, sobre todo, un carácter colonial- y Prusia, por su parte, aprovechaba su alianza con Francia para invadir y conquistar Silesia.

En un primer momento los progresos de las armas "galispanas" se tradujeron en el escenario del Norte de Italia en la conquista casi completa de la Lombardía, incluida Milán (16 de diciembre de 1745). Pero esta hegemonía era un espejismo. Carlos VII había fallecido ese mismo año, dejando a los aliados sin pretendiente con derechos defendibles al trono austríaco. Además, la defección de Prusia (que hace la paz por el Tratado de Dresde de 25 de diciembre de 1745 , una vez reconocidas y sancionadas sus conquistas) obligaría a los galos a entrar en negociaciones con Cerdeña, a la que llegarán a ofrecer, a espaldas de España, la mejor parte del territorio arrebatado a los austríacos. Ante la maniobra, Felipe $\mathrm{V}$ hará lo propio: enviará al abate Grimaldi a Viena con intención de llegar a un arreglo particular con la emperatriz.

Esta primera intentona de alcanzar la paz, nacida de las disensiones entre los Borbones, sólo logrará reforzar a sus enemigos. La situación dará un vuelco espectacular tanto por la desconfianza mutua en el ejército "galispano" como por la llegada al frente de nuevas tropas austríacas, liberadas del frente prusiano. Las pérdidas en Lombardía intentarán ser compensadas con las posesiones austríacas en Flandes; pero Francia sólo conseguirá acelerar las ansias por la paz en todo el continente, al amenazar Holanda con sumarse a la lista de rivales, ante el peligro de ver tropas francesas tan próximas a sus fronteras.

\section{La muerte de Felipe V}

En esta coyuntura cada vez más crítica (derrota del ejército "galispano" en Plasencia, 13 de junio de 1746) se produjo el fallecimiento de Felipe $\vee$ ( 9 de julio). Con este hecho y la llegada al trono de Fernando VI desaparecía el prin- 
cipal motivo que había empujado a España al conflicto. Era la primera consecuencia del nuevo reinado. Los intereses del monarca estaban muy distantes de los de su padre: "Pois agora sao os intereses muito diferentes dos que athe agora aquí reinavao, e el Rey he espanhol e muito espanhol de coraçao; e nada frances" ${ }^{\prime 1}$. Pronto él mismo señalaría las bases de su política: "no ser gobernado por Francia" y no tener "guerra con nadie" 2 .

Las alteraciones no se quedaron ahí. Fernando ordenaba a su madrastra que se retirase definitivamente al Palacio de La Granja de San Ildefonso, tras haber estado separada de la corte casi un año en el de los Afligidos -por el nombre de la plazuela donde se situaba el palacio-, cortando así de raíz cualquier posibilidad de interferencia de la "vieja leona" en los asuntos de gobierno. Le seguía todo un séquito de cortesanos entre los que se encontraban algunas de las figuras que mayor peso político habían poseído en los últimos compases del reinado de Felipe V. Así por ejemplo el conde de Montijo. Era sólo el comienzo de la purga que orquestarían los nuevos hombres de confianza de los reyes, sobre todo D. José de Carvajal y Lancáster, el nuevo ministro de estado.

La caída del "partido de los vizcaínos", liderado por Villarias y Arizaga (antiguo ayo del rey) ${ }^{3}$, fue otra de las consecuencias importantes del advenimiento. Nuevas aspiraciones políticas serían dirigidas por nuevos hombres. La suspicacia de Bárbara hacia los colaboradores de la reina madre, hacia quien sospechaba mantendrían su lealtad a pesar de la mudanza en la corona, le llevó a encumbrar en este comienzo de reinado al extremeño. Carvajal aprovechó los vientos favorables para consolidar su posición a base de colocar a sus par ciales en puestos claves de la red diplomática y de la administración. Sotomayor en Lisboa, el duque de Huéscar en París y Masones de Lima fueron algunos de sus clientes. El propio Ensenada, consciente de la debilidad de su posición -era un hombre proveniente del régimen anterior- sobreviviría políticamente gracias a su intervención:

"Te aseguro que en los principios B. me debió enteramente la vida civil y después muchas veces la conservación de ella"4

Esta revolución condicionó totalmente la continuación del conflicto. Los que habían sido rivales de Felipe $\mathrm{V}$ eran conscientes de ello por lo que se reto-

1. Bárbara de Braganza a Juan V, 22 de julio de 1746, PINTO FERREIRA, J. A., Correspondência de D. Joâo V e Dña. Bárbara de Braganza, Raínha de Espanha, 1746-47. Coimbra, 1945, p. 364.

2. GOMEZ URDAÑEZ, J. L., Fernando VI. Madrid, 2001, p. 46.

3. Integrado además por otros personajes importantes como los embajadores Scotti (Venecia) o Campoflorido (París), o nobles como Medinaceli, Montijo, Maceda, Mirándola, Palma o San Juan, según GOMEZ MOLLEDA, M. D., "El marqués de la Ensenada a través de su correspondencia íntima". Eidos 2 (1955), pp. 48-90.

4. "B." es uno de los sobrenombres de Ensenada en la correspondencia de Carvajal y Huéscar entre 1746 y 1749. GOMEZ URDAÑEZ, J. L., Fernando VI, p. 50. 
maron las conversaciones con España, tanto en Viena, en donde la emperatriz mandó negociar con Grimaldi, como en Lisboa, para donde partieron desde Londres el embajador Benjamin Keene y un exiliado español, el marqués de Tabuérniga ${ }^{5}$. A estas conversaciones se unieron Sotomayor, el recién nombrado embajador español en Lisboa, y Rosenberg, el enviado austríaco.

Estos intentos preliminares tuvieron un éxito limitado. Se derivó esta circunstancia de los desastres de las armas hispanas en Italia, que mediatizaban por completo el tablero internacional, colocando a Fernando VI en una posición desde la que poco se podía exigir. El intento de mediación de Juan $\mathrm{V}$, en nombre de su hija, y las conversación de Breda (cerradas en mayo de 1747) siguieron el mismo derrotero ${ }^{6}$. El fin de las hostilidades, que parecía tan cercano, se escapaba tercamente ante los ojos de las principales cortes europeas. Sin embargo el deseo de los nuevos monarcas hispanos y de sus ministros también era perseverante. Carvajal era consciente de cuál era el principal obstáculo a vencer para alcanzar su objetivo: Inglaterra. Sin embargo siempre había sido optimista al respecto: "Paréceme que no hay embarazo ni vencible para nuestra recíproca alianza con los ingleses y que hay conveniencias de ambos ${ }^{\prime \prime}$. Será ese sentimiento el que le llevará a idear una solución para evitar la ruptura definitiva del maltrecho entendimiento.

\section{D. Ricardo Wall}

Las remodelaciones de 1746 también afectarían particularmente a la vida de D. Ricardo Wall. Nacido en Nantes el 5 de noviembre de 1694, hijo de exiliados jacobitas irlandeses, había pasado al servicio de España, como tantos otros compatriotas, tras la muerte de Luis XIV y el cambio de orientación política del nuevo regente, Felipe de Orleáns, que había convertido en non grata la presencia de los refugiados jacobitas en Francia. Con recomendación de la duquesa de Vendôme, a la que había servido en calidad de paje desde aproximadamente 1710 , fue seleccionado para ingresar en el cuerpo de guardiamarinas ${ }^{8}$.

La carrera militar de Wall al servicio de España entroncaba con la antigua tradición de los Wild Geese, los mercenarios irlandeses que llevaban sirviendo

5. Sobre la misión de Keene, LODGE, R., The private correspondence of Sir Benjamin Keene. Cambridge, 1933, pp. 203-214.

6. Las gestiones de Macanaz en Breda aparecen esbozadas por OZANAM, D., La Diplomacia de Fernando VI. Correspondencia entre Carvajal y Huéscar, 1746-1749. Madrid, 1975, pp. 28-31. Ver también GOMEZ MOLLEDA, M. D., "El “caso Macanaz" en el congreso de Breda". Hispania 18 (1958).

7. DELGADO BARRADO, J. M., José de Carvajal y Lancáster. Testamento político o idea de un gobierno católico (1745). Córdoba, 1999, p. 22.

8. Estos y otras datos biográficos pueden verse en TELLEZ ALARCIA, D., "El caballero D. Ricardo Wall y la conspiración antiensenadista", DELGADO BARRADO, J. M. y GOMEZ URDAÑEZ, J. L. (coords.), Ministros de Fernando VI. En prensa. 
los intereses de las potencias europeas desde hacía más de un siglo. Su ascenso en el escalafón fue lento y arduo, e incluyó el paso por el cuerpo de guardiamarinas, el de infantería (1719-21) y el de dragones, en el que finalmente se estabilizaría. Participó en las campañas de Sicilia (1718-20), Ceuta (1720-21), Toscana (1731-33), Nápoles y Sicilia (1734-35) ${ }^{9}$. Tras más de veinte años de servicio por fin dirigía un regimiento en la de Lombardía, el de Francia, al mando del cual se había destacado en la toma de las ciudadelas de Montalbán y Villafranca o en el ataque a Bordiguera. El infante D. Felipe, al parecer, "lo empleaba con frecuencia en los ataques de audacia" ${ }^{\prime 10}$.

Aunque los méritos de Wall habían ido creciendo paralelamente a la madurez que le había dado la edad, fue el patrocinio de los nuevos hombres fuertes de la corte el que le permitió abordar nuevos retos, lejanos de las trincheras y más próximos a los despachos y gabinetes cortesanos. Muy próximo a la casa del duque de Liria por su análogo origen (había acompañado al duque en su misión a Rusia en 1727 y había sido su edecán en Nápoles en 1735) 11, también entró en los círculos del duque de Huéscar gracias a él, puesto que su hijo había contraído matrimonio con la hermana de éste.

Huéscar pronto quedó prendado del "don de gentes" del irlandés y de su "capacidad para cualquier encargo"12, virtudes que destacaban aquellos que le conocían. Ante la remodelación burocrática que acometía su otro íntimo, Carvajal, el duque, consciente de la escasez de peones leales a los nuevos hombres fuertes del gobierno, recomendaba vivamente a Wall:

"Mira que en el ejército tienes una cosa muy buena que es Wall, así en lo honrado como en lo capaz. Puedes seguramente echar mano de él para negociaciones y suplir el defecto de extranjero, porque le tengo muy probado y conozco te hallarás mejor con él que conmigo mismo. Si para tenerle a la mano te parece echarle acá, sea para el futuro congreso o para otra parte y no te pareciere mal mi pensamiento, mándale venir"13.

Su único defecto es, para Huéscar, el ser extranjero. Un punto débil demasiado suculento para los posibles futuros enemigos, máxime hallándonos en un

9. A.G.S., Secretaría de Guerra, 2.465, libreta II, hoja 12, libreta III, hoja 10 y libreta IV, hoja 10 .

10. COXE, G., España bajo el reinado de la casa de Borbón, desde 1700 en que subió al trono Felipe V, hasta la muerte de Carlos III, acaecida en 1788. Madrid, 1846, Tomo III, n. 249.

11. El duque de Liria, posteriormente de Berwick era nieto de Jacobo II. Su viaje a Rusia y el papel de Wall puede verse en "Diario del viaje del Duque de Liria y Xérica" en Colección de Documentos Inéditos para la Historia de España. Tomo XCIII, Madrid, 1889. Su relación en Nápoles: D. Andrés Benincasa a Patiño, Madrid, 19 de julio de 1735, A.G.S., Secretaría de Guerra, 1.040.

12. "Cosme es capacísimo y tiene don de gentes", Huéscar a Carvajal, 17 de octubre de 1747, OZANAM, D., La Diplomacia..., p. 237.

13. Huéscar a Carvajal, 14 de mayo de 1747, OZANAM, D., La Diplomacia..., pp. 193-194. 
país del que Tanucci decía, "no quieren ni sufren héroes ni forasteros"14. El ministro, con todo, aceptará el consejo del aristócrata: "el que me decías (Wall) va a Génova" ${ }^{\prime 15}$. Con su fichaje, podía empezar a jactarse de haber formado su propia facción: "Ya me ves que a él (Masones) y a Wall (...) los he metido en nuestra cofradía"16.

Génova era una de las esperanzas hispanas para la campaña de 1747. Los desastres del año anterior habían afectado a la república, que había sido abandonada al ejército austríaco. Sin embargo a comienzos de 1747 la ciudad se resistía al enemigo, a pesar de estar sitiada, y prometía un posible desquite a sus aliados, los Borbones. El cometido de Wall sería exclusivamente militar. Debía cuidar del buen uso y correcto aprecio de los socorros enviados por Fernando $\mathrm{VI}$, asistir a los consejos de guerra, limar las asperezas entre las tropas españolas y las francesas e informar de todo al marqués de la Mina y a Carvajal ${ }^{17}$.

A la luz de estos objetivos y de la vida que iba a hacer en la plaza, poco parecía haberse apartado su vida de la castrense con este nombramiento:

"Concluí esta mañana el día de mi servicio algo fatigado a causa de la incesante vigilia con que ha sido preciso más que nunca estar en virtud de el tal cual juicio que se ha hecho del embarco que se ha confirmado de algunos cañones de los enemigos o bien de alguna intentona que piensan hacer, según acostumbran. Pero ha querido Dios se hayan mantenido con alguna tranquilidad en esta parte" ${ }^{18}$.

Pero éste era un destino pasajero. Carvajal, una vez probada su valía, tenía en mente proyectos más ambiciosos para capitalizar sus talentos:

"Hállase en D. Ricardo Wall, sobre su talento y experimentada fidelidad, la circunstancia no común de saber esa lengua y ésta era esencialísima para poder lograr el acceso a los ministros, sin que fuese público que están ahí, lo que por muchas razones se creyó necesario y así se determinó el Rey a que fuese elegido"19.

\section{La misión secreta en Inglaterra (1747-1748)}

El fracaso de las negociaciones en Lisboa no había disuadido por completo a Carvajal de la posibilidad de llegar a un acuerdo con Inglaterra. A su juicio

14. Tanucci a Centomani, 6 de agosto de 1763, citado por DANVILA Y COLLADO, M., Reinado de Carlos III. Madrid, 1891-94, Tomo II, p. 238. Los españoles los "acogen con tanta menor simpatía cuanto más alejados se encuentran de la esfera gubernamental", SARRAILH, J ., La España Ilustrada de la segunda mitad del s. XVIII. Madrid, 1974, p. 336.

15. Carvajal a Huéscar, 22 de mayo de 1747, OZANAM, D., La Diplomacia..., p. 196.

16. Carvajal a Huéscar, 29 de mayo de 1747, OZANAM, D., La Diplomacia..., p. 200.

17. Orden para que D. Ricardo Wall pase como ministro a Génova, 16 de mayo de 1747, A.G.S., Estado, 6.913. El sitio de la ciudad se levantó la noche del 5 al 6 de julio, apenas unos días después de la marcha de Wall.

18. Wall a Carvajal, 23 de junio de 1747, A.G.S., Estado, 6.913.

19. Carvajal a Tabuérniga, 27 de diciembre de 1747, A.G.S., Estado, 6.913. 
había sido el embajador austríaco en la capital lusa, Rosenberg, quien había boicoteado las conversaciones, siendo enviado explícitamente a ellas con tales propósitos, dada la intención de retardar al máximo la solución del conflicto en un momento en el que la suerte sonreía a sus armas:

"No hay que dudar que es paso que importa infinito y que acaso nos hubiera librado de esta campaña hecho antes, porque en Lisboa hacen burla de los viejos (Da Mota y Sotomayor) y con razón, que están chochos y rechinosos conmigo terriblemente y tímidos de decir que no se habla de ajuste separado"20.

El ministro había creído vislumbrar además una pequeña apertura de las posiciones británicas, que se corroboraría con la presentación de un proyecto de paz por Keene en Lisboa ${ }^{21}$, demostrando así la buena voluntad de su gobierno. Su deseo de entablar conversaciones directas y sin intermediarios le llevó a "enviar un hombre a Londres para que tantee aquella corte y sepamos a dónde llegan sus pensamientos"22. Ese hombre sería Wall.

Abandonar la ciudad italiana se convirtió en una prioridad difícil de cumplimentar con decoro. Llegado el 8 de junio, apenas un mes después se le notificaba su nueva misión. Carvajal se lo indicaba a Huéscar del siguiente modo: "Wall saldrá de Génova con motivo de falta de salud y marchará presto"23. El pretexto se buscó cuidadosamente ya que por un lado no se pretendía herir la sensibilidad de la república y por otro no se deseaba levantar sospechas en otras potencias. Ya que Wall había estado convaleciente en Montpellier de diversas heridas producidas en la batalla de Plasencia hasta al menos enero de $1747^{24}$, fue factible presentar esta excusa para su salida: un empeoramiento de su salud y la necesidad de tomar las aguas medicinales de Aix para mejorarla ${ }^{25}$. El 22 de junio, Mina había escrito en ese sentido al irlandés ${ }^{26}$, llegando éste al cuartel general de Menton a principios de julio. El 8 del mismo saldría hacia París, adonde llegaría el 21. De allí saldría el 23, con destino al cuartel general en Flandes, Tongres, donde se hallaba Huéscar y los principales ministros france-

20. Carvajal a Huéscar, 23 de junio de 1747, OZANAM, D., La Diplomacia..., p. 205.

21. Extrait d'un projet de traité préliminaire (...) pour etre remis à la cour d'Espagne, 18 de junio de 1747, A.H.N., Estado, 4.166.

22. Carvajal a Huéscar, 23 de junio de 1747, A.H.N., Estado, 4.166.

23. Carvajal a Huéscar, 5 de julio de 1747, OZANAM, D., La Diplomacia..., p. 209.

24. "Habiéndome aprovechado los remedios y el descanso que he tomado en esta ciudad me hallaba ya con bastante robustez para tomar la resolución de restituirme al ejército", Wall a Carvajal, Montpellier, 7 de enero de 1747, A.G.S., Estado, 6.913.

25. "Il se trouve en convalescence à Montpellier lorsqu'il est chargé d'une commission secrète tendant à explorer les possibilités d'une paix séparée avec l'Angleterre (28 mai 1747). Sous couvert d'une affectation fictive à Genes, il arrive dans cette ville le 8 juin et en repart au début de juillet sous preétexte d'aller rétablir sa santé aux eaux d'Aix-la-Chapelle", OZANAM, D., Les diplomates espagnols du XVIIIe siècle. Madrid, 2000, p. 471.

26. Mina a Wall, 22 de junio de 1747, A.H.N., Estado, 4.103. 
ses. Allí sería instruido por sus mentores en la forma en que se deseaba se condujese en este encargo.

Los despachos de Carvajal de agosto contenían su espíritu fundamental. Las instrucciones eran muy similares a las que tenía Sotomayor en Lisboa para tratar con Keene en lo tocante a propósitos, pero muy diferente en su contexto. Fernando VI insistía a Wall que deseaba "que la paz sea general, concluyendo los empeños en que me hallo concorde y de acuerdo con la Francia (...) en cuya suposición trataréis ${ }^{\prime 27}$. Es decir, Wall debía negociar los litigios pendientes de las dos coronas con Inglaterra. Por parte de España, la posible devolución de Gibraltar y el establecimiento del infante prioritariamente, la rescisión del Asiento de Negro y del Navío de Permiso en un plano secundario. Por parte de Francia, la restitución del Cabo Bretón y el comercio en la ciudad de Dunquerque. Sólo en un último caso, y tras hacer todos los esfuerzos por un arreglo general, podría intentar un arreglo particular hispano-británico, marginando a Francia.

El paso por Tongres era por tanto premeditado. Si Wall iba a negociar en nombre de Francia, debía entrevistarse con sus ministros. Puyzieulx, ministro de asuntos exteriores que había sucedido a Argenson, se expresaba así ante la iniciativa de Carvajal:

"Je me suis contenté de luy répondre que (...) nous verrions sans jalousie (...) que S.M.C. eut tout I'honneur de la pacification pourvu qu'elle ne conclue rien à cet égard indépendamment de nous et à nostre insçu" ${ }^{\prime 28}$.

Pero no engañaba a Huéscar que conocía de sobra sus reticencias:

"Conozco que el haberse conformado Puyzieulx en que tratemos con los ingleses es por sacar el cuerpo fuera, pero yo me he hecho desentendido porque nunca vamos a perder en tantear para conseguir o desengañarnos. Lo que es gracioso es que este hombre ha hecho de la necesidad virtud y me ha dicho que tratemos por ellos debajo de los principios que no ignoramos. De todo esto se puede hacer buen uso si las cosas se ponen bien en Londres, y si no salen bien, nunca estaremos peor que ahora" ${ }^{29}$.

E incluso había tenido que negociar duramente con él algunos de los puntos, como la posibilidad de que España reclamase Gibraltar, que admitió aun-

27. Instrucción de Wall, 4 de agosto de 1747, A.H.N., Estado, 4.166.

28. Puyzieulx a Vauréal, 29 de julio de 1747, Archives du Ministère des Affaires Etrangères, París (en adelante A.E. Paris), Correspondance politique, Espagne, 495, fs. 127-134.

29. Huéscar a Carvajal, 12 de junio de 1747, OZANAM, D., La Diplomacia..., p. 202. Siguiendo las indicaciones de un despacho de Carvajal del 28 de mayo, Huéscar hizo que Puyzieulx admitiera el que España pudiere enviar un emisario a Londres, no sólo para ver las posibilidades que había de separar a Cerdeña de Austria en lo concerniente al establecimiento sino también para tantear el terreno sobre la restitución de Gibraltar (Huéscar a Carvajal, 12 de junio, A.H.N., Estado, 4.093). Aprovechando estas buenas disposiciones, el embajador había escrito a Mina que le enviara a Wall inmediatamente (Huéscar a Mina, 12 de junio, A.H.N., Estado, 4.103). 
que asegurándole que "su amo no hará una campaña más porque Gibraltar entre en nuestro poder" ${ }^{\prime 30}$.

En Tongres, Carvajal instruyó a Wall, a través de diversos despachos, en un sinfín de prudencias. La clave del encargo estaba precisamente en su disimulo, en su capacidad de pasar desapercibido y no levantar sospechas entre los aliados de Gran Bretaña, Austria y Cerdeña sobre todo. Wall pasaría a las islas bajo el disfraz de un tratante de caballos asentado en España, Ilamado Mr. Lemán (uno de los sobrenombres con el que le mencionaban, entre otros, como "Cosme" o "Dragón", en su correspondencia, Huéscar y Carvajal) ${ }^{31}$, que había viajado a Inglaterra para cerrar diversos negocios. Su correspondencia, totalmente cifrada, se enviaba normalmente a través del Canal a Holanda, en concreto a Amsterdam o a La Haya, en donde un agente suyo, Daniel Ferrand, gestionaba su reenvío de incógnito a París, en donde la recibía Huéscar. El duque era el enlace entre Carvajal y el irlandés, que durante meses no tendrían correspondencia directa dada la necesidad de mantener el secreto de la misión. Sin embargo cabía la posibilidad de precisar envíos extraordinarios y más veloces:

"Por si ocurriese alguna precisión o precisiones que no se puedan prevenir en que crea V.S. deber despachar acá sin que pase por otro territorio, le incluyo cuatro salvoconductos y otras tantas cartas mías para que pueda enviar un paquebote a alguno de nuestros puertos. No envío a V.S. correos porque no le descubran y embaracen" ${ }^{\prime 2}$.

Gran parte de las providencias se encaminaron a mantener el incógnito de la misión, sobre todo frente a los austríacos:

“Prevenir a V.S. que el ministro que tiene la corte de Viena en esa donde V.S. va es muy hábil y estimado, conque conviene mucho recatarse de él (...) Donde le parezca a V.S. que le miran con misterio procure hacerse tener por francés, que esto importa menos que el que le crean español"33.

Había llegado incluso al extremo de obtener el dinero para la misión a través de un crédito de 300 mil reales obtenido en Francia porque "aquí no se podía sacar letra por que no se publicase". Y sin embargo él mismo se había visto obli-

30. Huéscar a Carvajal, 21 de julio de 1747, A.H.N., Estado, 4.090.

31. "Quedemos en entendernos para nombrar a Wall "Cosme" y donde va "las Batuecas" y Lisboa "la Abadía" y se podrá decir algo que entendamos los dos", Carvajal a Huéscar, 18 de agosto de 1747, OZANAM, D., La Diplomacia..., p. 221.

32. Carvajal a Wall, 6 de agosto de 1747, A.G.S., Estado, 6.913. Entre estos despachos del 6 de agosto también se encontraba la cifra y los salvoconductos que menciona. Uno de ellos rezaba: "Cualquiera Gobernador o ministro del rey que mandare en el puerto o rada donde llegare una embarcación de cualquier nación que sea, aunque se esté en guerra con ella y le entregare esta mi carta dirigirá inmediatamente con la mayor seguridad y diligencia a mis manos los pliegos que con ella vinieren, guardando secreto inviolable que así lo manda el Rey".

33. Carvajal a Wall, 6 de agosto de 1747, A.G.S., Estado, 6.913. 
gado a revelar la misión en Lisboa para no levantar recelos en la corte vecina, tan influyente en estas fechas en la española a través de la reina Bárbara:

"He permitido que diga en gran secreto esta corregidora a la de la Abadía que ha ido Cosme a las Batuecas a petición de los amigos y que lo calle, porque se ha temido que lo sepa y se ofenda" ${ }^{\prime 3}$.

Pero no todas las providencias del ministro se encaminaban a este extremo. Otro de los factores determinantes para el éxito de la misión era la correcta información. Para que Wall estuviera perfectamente al corriente del desarrollo de las negociaciones anteriores adjuntó en uno de sus despachos del 6 de agosto una relación con los sucesos de las conversaciones de Lisboa, de modo que el irlandés tuviese claro cuál era el punto de partida y cuáles las objeciones principales de los ingleses. Para completar esta panorámica, días después le remitió nuevos datos:

“(...) incluyo esos tres tomos del estado político que los refieren con toda individualidad (...) los debates que ha habido en los parlamentos de Inglaterra en los depuestos partidos, sobre las diferencias con nosotros ${ }^{\prime 35}$.

También le hacía otro tipo de recomendaciones para que obtuviese información previa por canales imparciales acerca de las pulsiones de la opinión pública. La bolsa y los cafés eran para él los termómetros perfectos para tal cometido:

"Ofréceseme que, si no hay peligro en su persona ni en que sea descubierto del público, pudiera conducir estarse unos días sin manifestarse del ministerio, tomando en la Bolsa y en los cafés con el auxilio de la lengua una idea del estado de ese gobierno" ${ }^{\prime 36}$.

Para finalizar Carvajal le indicaba la posibilidad de encontrar un colaborador útil en la capital del Támesis. Alguien acostumbrado a la city, un perfecto conocedor de la situación socio-política del país y de los principales poderes en la corte y el parlamento, un informador, un as oculto, si bien un as arriesgado: el marqués de Tabuérniga. Este había llegado incluso a ofrecer su casa para hospedar al enviado en Londres, si bien Carvajal recelaba de sus intenciones y de la utilidad que Wall podía sacar de sus oficios:

"Yo no le conozco; algunos me dicen que tiene advertencia pero ligereza también, si él pudiere ser útil válgase V.S. de él, que como haga servicios apreciables, el Rey se los remunerará con toda su proporción" ${ }^{\prime 37}$.

34. Carvajal a Huéscar, 21 de septiembre de 1747, OZANAM, D., La Diplomacia..., p. 230.

35. Carvajal a Wall, 14 de agosto de 1747, A.G.S., Estado, 6.913.

36. Carvajal a Wall, 6 de agosto de 1747, A.G.S., Estado, 6.913.

37. Carvajal a Wall, 6 de agosto de 1747, A.G.S., Estado, 6.913. El embajador francés en España, Vauréal, halla en él "de l'esprit, de l'audace, beaucoup d'intrigue et d'artifice et peu de délicatesse sur la vérite et le choix des moyens pour parvenir à ses fins", Vauréal a Amelot, 24 de agosto de 1742, A.E. Paris, Correspondance politique, Espagne, 471, fs. 285-286. 
Por lo que puede observarse, el esfuerzo planificador de la pluma de Carvajal fue ingente, lo que nos da una ligera idea de las esperanzas que puso en el proyecto. El mismo se lo reconocía a Huéscar: "Si no esperas mucho de Cosme estamos discordes en el juicio" ${ }^{\prime 38}$. Pero el duque tenía tantas esperanzas como su amigo: "Wall marchará el domingo sin falta ¡Dios le dé acierto y disponga las cosas de modo que pueda aprovechar sus luces, que son conocidas y sobresalientes!" ${ }^{39}$. Efectivamente al día siguiente de escribir estas palabras, Huéscar se despedía de Wall. Tenía que atravesar el frente, para lo que tuvo que servirse de nuevos salvoconductos ${ }^{40}$. El 15 de septiembre se embarcaba en Holanda y el 18 llegaba a Londres. El marqués de Tabuérniga, su contacto, le esperaba.

\section{El marqués de Tabuérniga}

D. Jaime Velaz de Medrano tenía una azarosa historia tras de sí. Aristócrata, teniente del regimiento de Guardias españolas, había sido juzgado y encarcelado en 1731 por conspirar contra Felipe V. Descontento con su poca introducción en la corte había osado tratar de mover el ánimo del infante D. Fernando para que huyera a Portugal y reclamase el trono con la ayuda de su cuñado. Esgrimía como justificante de sus palabras el lamentable estado de la monarquía, pero sobre todo, la promesa del monarca de cederle el trono en cuanto la edad lo permitiera, circunstancia que "ya se ha cumplido, pues ya igualó la de V.A. a la del señor D. Luis Primero" ${ }^{\prime 41}$. Fernando sin embargo había denunciado el manejo, lo que le había costado la prisión en Vélez de Málaga.

El marqués era sin embargo ambicioso. La cárcel no era un obstáculo excesivo para un aristócrata, cuyo título le permitía vivir en una suerte de régimen abierto muy permisivo. Durante los siete años que estuvo en estas circunstancias se le conocen diversas salidas a Málaga, sobre todo en el último periodo. D. Jaime había encontrado una candidata perfecta para desposarse, la hija de los marqueses de Fuensol, Dña. Ana Bracamonte, debido a su abultada dote, "una de las mejores del reino", como él mismo asegura. Era la oportunidad de implorar la "augusta clemencia" de los monarcas y pedir la licencia regia para el casamiento ${ }^{42}$.

La fortuna no estuvo de su parte. Negada la licencia e internada Ana en un convento por seguridad, Tabuérniga no tuvo remordimientos para huir de Vélez con la hermana de la pretendida, Petronila Bracamonte, con la que pasó a

38. Carvajal a Huéscar, 21 de septiembre de 1747, OZANAM, D., La Diplomacia..., p. 230.

39. Huéscar a Carvajal, 27 de agosto de 1747, OZANAM, D., La Diplomacia..., p. 225.

40. Wall a Carvajal, Tongres, 26 de agosto de 1747, A.G.S., Estado, 6.913. Informa de que pasará por Lieja, donde se halla el cuartel del general Ligonier, para recoger el pasaporte que necesita para ir a Inglaterra. Hasta allá usará el del duque de Cumberland.

41. A.G.S., Estado, 5.899.

42. Tabuérniga a Isabel Farnesio, 16 de julio de 1737, A.G.S., Estado, 5.899. 
Gibraltar disfrazándola de hombre. El matrimonio se sancionaría en la iglesia católica de la roca. Como él mismo reconocía, había demasiados intereses para dejar pasar semejante oportunidad:

“(...) pues para la importancia de nuestro pundonor, lo mismo era casarme con esta hermana que con la otra, y cumpliendo así con la razón de estado de nuestras familias no faltábamos a la obediencia de nuestros soberanos pues para esta dama como no se había pedido licencia no la habían negado sus majestades" ${ }^{\prime 3}$.

Era una astuta pirueta para evadirse de las obligaciones de su título. No obstante su desobediencia le costaría el exilio. Primero en Gibraltar, luego en Lisboa y finalmente en Londres. Sus diversas tentativas para reconciliarse con los monarcas fueron acogidas con frialdad. En 1740, desencadenada la guerra colonial Ilamada de la Oreja de Jenkins entre España e Inglaterra, escribía a Villarias pidiéndole le nombrase embajador en Londres. Es evidente que el marqués veía en el conflicto la mejor oportunidad de demostrar a la corte hispana sus capacidades y su lealtad procurando el arreglo y, a la vez, redimiéndose . Sería este sentimiento una constante durante el resto de la década.

Pero mientras Ilegaban mejores noticias de la Península, había que sobrevivir:

"The marquis of Tabuerniga was a Spanish noble with a taste and some talent for intrigue. (...) Driven into exile, Tabuerniga went to England, where he played a curious underground part for the next eight years. George II gave him a pension of 600 pounds a year, but he also established relations with the Prince of Wales, who allowed him another 400 pounds. In the Leicester House circle he acted as a spy for Newcastle" ${ }^{\prime 4}$.

No es de extrañar que Carvajal, por un lado, precisase su ayuda y su perfecto desenvolvimiento en las altas esferas del gobierno británico y, por otro, desconfiase.

Esta posición privilegiada y sobre todo el patrocinio del duque de Newcastle, ministro principal del gabinete inglés, le concedió diversas oportunidades para colaborar en el acercamiento de posturas entre España e Inglaterra. En agosto de 1746 fue de hecho enviado a Lisboa oficiosamente para preparar la llegada de Keene, el auténtico negociador. Ante la evidencia del fracaso, presionó a Carvajal para que le permitiese regresar a Madrid para Ilevar personalmente las conversaciones ${ }^{45}$. Denegada la merced, retornó a Inglaterra a comienzos de 1747. Una nueva decepción.

Pero Tabuérniga era tenaz. Consciente del profundo deseo de Carvajal de alcanzar el tan deseado entendimiento anglo-hispano, aún aspiraba a ser su instrumento, si no en Madrid, al menos en Londres. Nadie como él había cultivado

43. Memorial de Tabuérniga a Jorge II, A.G.S., Estado, 5.899.

44. LODGE, R., The private..., p. 100, n. 1.

45. Así se lo indica Carvajal a Wall, 6 de agosto de 1747, A.G.S., Estado, 6.913. 
la intriga y el disimulo en la corte de Jorge II. Pocos en España le igualaban en astucia y capacidad. Y menos aún eran capaces de explicarse con solvencia en inglés, cualidad nada despreciable cuando de pasar desapercibido se trataba.

La impresión que causó en el marqués la elección de D. Ricardo Wall y el resentimiento que acarreó debieron de ser doblemente profundos. Según Wall ambos habían sido amigos en el pasado ${ }^{46}$. Sin embargo en 1727, Tabuérniga había perdido la oportunidad de acompañar al duque de Liria a Rusia ${ }^{47}$, en circunstancias poco claras, habiendo recaído en Wall, entre otros, el honor de hacerlo. En esta ocasión se hallaba frente a una terrible disyuntiva: aceptar la derrota y ayudar en lo posible al agente con la esperanza de ganarse la redención o bien dejarse llevar por el encono y tratar de socavar en todo lo posible el apoyo de sus jefes, desacreditándole, en la confianza de ser el siguiente en la lista. Lo paradójico del caso es que Tabuérniga, en una situación, como se ve, bien confusa, en lugar de optar con claridad por una de ellas, ejercitó taimado ambas a la par.

\section{Vicisitudes y fracaso de la misión}

El grado de dificultad del encargo no había sido, a pesar de las precauciones, calibrado con exactitud. En primera instancia existían pequeñas complicaciones de tipo logístico en las que no se había reparado. Si las precauciones debían mantenerse inalterables al arribo a Londres, era imposible hacerlo sin la más mínima ayuda: "Te incluyo las copias de las cartas de Cosme. Su corregimiento ha sido bien recibido, pero yo estoy mal con que no me haya escrito en cifra. Así se lo advertiré aunque me hago cargo que está solo"48. El irlandés no llevaba consigo secretario alguno que le ayudase con el despacho por lo que resultaba difícil mantener una correspondencia eficaz, sobre todo si había que cifrarla. Su primera carta desde Londres dejaba muy clara la necesidad que tenía de ayuda:

"La carta es para el Sr. Dn. José de Carvajal; va cifrada con la cifra de V. E. para que se entere de su contenido y lo exponga a S. E. por serme imposible mantener la correspondencia con ambos a lo menos por este coreo; necesito alguno para ayudarme o me mato si hay algo que hacer" ${ }^{\prime 4}$.

Para solucionar este problema, Wall pidió que se le enviase a un antiguo colaborador Agustín Alegre, a quien había dirigido en su regimiento y que le

46. "He visto a Tabuérniga, antiguo amigo mío, pero ha diez y siete años que no le trato", Wall a Huéscar, 25 de septiembre de 1747, A.H.N., Estado, 4.264..

47. Por culpa de "una calumnia que al declarante le levantaron por la cual se le suspendió su viaje a Moscovia con el duque de Liria el año de setecientos y veinte y siete", A.G.S., Estado, 5.899 .

48. Huéscar a Carvajal, 11 de octubre de 1747, OZANAM, D., La Diplomacia..., p. 233.

49. Wall a Huéscar, 22 de septiembre de 1747, A.H.N., Estado, 4.264-1. 
había acompañado a Génova. Como militar que era también, Mina se opuso a desprenderse de alguien de su experiencia y valía. La insistencia de Wall y de Huéscar acabaron por vencer las reticencias del general ${ }^{50}$. Llegado a Niza el 7 de octubre y a Fontainebleau el 10 de noviembre, Alegre abandonó París el 17 con dirección a Holanda donde tuvo que esperar un pasaporte algunas semanas antes de poder instalarse en la capital inglesa, a donde llegó el 10 de diciembre de 1747.

El escollo principal no obstante radicaba en otras esferas: la del mantenimiento de la confidencialidad del encargo sobre todo. Para ello era fundamental ganarse la confianza del ministerio inglés con la intención de evitar que éste notificase a sus aliados las gestiones iniciadas por España. En la obtención de ese crédito es en donde debía trabajar con más ahínco, sirviéndose en lo posible de su dominio de la lengua y de la esperada colaboración del marqués de Tabuérniga.

Sin embargo los frutos fueron exactamente los contrarios. El origen del agente suponía un handicup añadido con el que no se contaba. Pronto se criticó que "para un negocio de tanto honor, confianza y gravedad no se hubiese enviado un buen español, sino a un irlandés nacido en Francia, por cuyas circunstancias le suponían enemigo de la Inglaterra" ${ }^{21}$. El pertenecer a una familia de reconocida fama jacobita no ayudaba en absoluto: "estos señores creen que tienen fundamentos cuando dicen que es más jacobita que el mismo pretendiente" ${ }^{\prime 52}$.

Tabuérniga, transmisor de estas noticias, comenzaba a alimentar y capitalizar la oposición de un gabinete inglés que precisamente un año antes había tenido que vérselas con un levantamiento projacobita en Escocia, en el que, además, habían participado algunos familiares del propio Wall ${ }^{53}$ :

"Yo hago lo posible para disuadir que Mr. Wall es un emisario francés más bien que español pero los argumentos y las reflexiones de estos señores que se fundan en los avisos que han tenido de diferentes particularidades y en la inclinación que dicen han observado en sus propios discursos no quieren acordarse con los míos en esto" ${ }^{\prime 54}$.

Sin embargo no era el único que apreciaba sus recelos:

50. "Hace alguna dificultad el marqués de la Mina en enviar a Alegre; pero le volveré a pedir, porque es servicio más útil el que hará con V.M.", Huéscar a Wall, 30 de septiembre de 1747, A.H.N., Estado, 4.264-1.

51. Tabuérniga a Carvajal, 3 de noviembre de 1747, A.G.S., Estado, 6.913. Como se ve todo un alegato en su propio favor.

52. Tabuérniga a Carvajal, 6 de abril de 1748, A.G.S., Estado, 6.913.

53. En concreto su primo, D. Patricio Wall, que tras el fracaso del mismo, pasó al servicio de Francia en cuyo ejército hizo carrera. Ver HAYES, R., Biographical dictionary of Irishmen in France. Dublín, 1949, pp. 304-305.

54. Tabuérniga a Carvajal, 10 de octubre de 1747, A.G.S., Estado, 6.913. 
"Desde mi arribo a esta ciudad me ha repetido Mr. Sandwich que la persona de D. Ricardo Wall no era de las mas agradables para con aquella nación porque sobre ser irlandés que no es para los ingleses de ninguna recomendación, tenía la cualidad de ser en el corazón verdaderamente francés y por consiguiente sospechosa cualquiera negociación que entablase ${ }^{\prime \prime 55}$.

E incluso el propio protagonista decía "reconocer sospecha en esta gente (de) que mi misión era por influjos de la Francia de quien no nos podíamos apartar; el ser yo irlandés daba así mismo desconfianza" ${ }^{\prime 56}$.

Parecía la oportunidad que esperaba el marqués. Aunque frente a Wall siempre mostraría una faz correcta y colaboradora, su correspondencia con Carvajal nos muestra una cara bien distinta. Su doble juego no tenía otro objeto que desacreditar de un modo definitivo al irlandés a través de las más variadas acusaciones:

“Este caballero está tan opuesto realmente a que hagamos la paz sin la Francia que por tantas cosas como me ha dicho sin variación en muchas ocasiones, irritado y lleno de fuego, que no repito a V.E. por faltarme tiempo y fuerza para escribir, se debe creer que querría que le cortasen la mano más bien que firmar con ella sin la Francia una paz entre nosotros la Inglaterra y sus aliados; y que bajo la máscara hipócrita del honor mal entendido se le descubre un ánimo no más sensible que el bronce (...) si por providencia del cielo yo no me hubiera hallado aquí le habrían despedido ciertamente al instante y él se hubiera vuelto gustoso a París para recibir las gracias y los aplausos de la corte de Francia, del Pretendiente, de Génova y de los irlandeses sus paisanos" ${ }^{\prime 57}$.

Era evidente que, el que se presumía colaborador, se había convertido en un obstáculo más de los que el agente debía superar para consolidar su posición en Londres. Carvajal, cuya confianza en Wall jamás se resintió, avisó pronto al irlandés de las circunstancias del marqués:

"Aunque él se lisonjea que a persuasión suya se ha enviado persona, se conoce bien que lo ha sentido mucho, de que se infiere que esperó que se le enviase encargos y poderes" ${ }^{\prime 58}$.

55. Masones a Huéscar, 28 de agosto de 1748, A.H.N., Estado, 4.142.

56. Wall a Huéscar, 27 de octubre de 1747, A.H.N., Estado, 4.264-1. Tabuérniga informa de que "el duque de Bedford, nuevo secretario de Estado (...) dijo el otro día que Mr. Wall no era otra cosa que un buen espión de la Francia y su buen agente", Tabuérniga a Carvajal, 6 de abril de 1748, A.G.S., Estado, 6.913.

57. Tabuérniga a Carvajal, noviembre de 1747, A.G.S., Estado, 6.913.

58. Carvajal a Wall, 24 de noviembre de 1747, A.G.S., Estado, 6.913. Efectivamente Tabuérniga se había adjudicado la paternidad de la idea: "Las instancias que yo hice por medio de V.E. para que el rey se dignase enviar aquí una persona de mérito y capacidad (como lo es Mr. Wall) que supiese aprovecharse de alguna ocasión favorable para salir de nuestro empeño con honor", Tabuérniga a Sotomayor, 10 de octubre de 1747, A.G.S., Estado, 6.913. 
Pero no podía prescindir de sus talentos. Así que recomendaba circunspección y tacto a su pupilo, quien la practicaba con diligencia: "como dice S.E. no hay necesidad que sepa más de lo que convenga a mis fines" ${ }^{\prime \prime 2}$. El ministro aprobaba su comportamiento:

"La de 10 contiene la conversación con Tabuérniga en que fue la conducta de V.S. acertadísima pues nada se puede perder en mantener con él reserva que, cuando no fuese infiel, pudieran padecer algún descuido o por ligereza natural o por demasiado celo de acá o por demasiado agradecimiento de allá"60.

La presunta francofilia -qué paradoja en alguien que ha pasado a la historiografía, con la misma injusticia, como anglófilo convencido- fue uno de los argumentos más esgrimidos para criticar la misión de Wall ${ }^{61}$. Como se desprende de lo dicho hasta ahora, ésta era tan sólo la lógica consecuencia de la obeciencia de sus órdenes: negociar en nombre del Católico pero sin perder de vista los intereses del Cristianísimo. Así lo afirmaba el propio Carvajal: "Nada me admira tanto como que esos señores concibiesen desconfianza de la persona porque si es por la firmeza en algunas proposiciones podían atribuirlo a instrucciones más que a inclinación suya" ${ }^{\prime 62}$. Pero a pesar de su firme defensa de la inocencia de Wall ${ }^{63}$, los prejuicios de los ministros ingleses obraron la temida revelación de la misión española a los aliados británicos. Tabuérniga en su línea de aprovechar cualquier noticia para su silenciosa enemiga, justificaba el hecho aludiendo a la dudosa discreción del agente o a su incontinencia verbal con gente "que le abastecen de sueños y delirios":

“(Wall) gustaba de concurrir en mi casa con gente de distinción, sabiendo que entre ellas había cuatro personas que le habían conocido personalmente en España, en Francia, en Italia y en Rusia; que iba públicamente a la comedia, y que entraba en los palquetes para hablar con las damas que había visto en mi casa, las cuales no dudaban que era persona de condición, pues aunque yo decía que era comerciante establecido en España, sus maneras y sus discursos le desmentían mostrando que era caballero y hombre político y militar (...) me hallo escarmentado de que habiéndole hecho algunas confianzas y pedídole que no se diese por entendido con estos señores, no se podía contener y les hablaba de ellas francamente con riesgo mío"64.

59. Wall a Carvajal, 28 de noviembre de 1747, A.H.N., Estado, 4.264-1.

60. Carvajal a Wall, noviembre de 1747, A.G.S., Estado, 6.913.

61. Sobre la anglofilia de Wall y sobre otros muchos tópicos extendidos por la historiografía sobre su figura puede consultarse: TELLEZ ALARCIA, D., "D. Ricardo Wall: Luces y sombras de un ministro", Monarcas, Ministros y Corte. La España de Felipe V y Fernando VI, Revista Códice. Universidad de Jaén, en prensa.

62. Carvajal a Tabuérniga, 22 de diciembre de 1747, A.G.S., Estado, 6.913. "Lo que V.S. recela culpas en D. Ricardo Wall han sido obediencias", le diría todavía el 4 de junio de 1748.

63. Carvajal pone fuera de toda duda su lealtad: "esté V.S. seguro de que Wall nada será, sino es lo que sea su amo, si el rey fuere francés lo será y si el rey fuere inglés lo será él, sin extraviarse a otro lado", Carvajal a Tabuérniga, 17 junio de 1748, A.G.S., Estado, 6.913.

64. Tabuérniga a Carvajal, 6 de abril de 1748, A.G.S., Estado, 6.913. 
Sin embargo hasta él mismo, observador nada imparcial, tuvo que reconocer que los ingleses habían desvelado "con recato" la presencia del agente a sus aliados, aunque, a continuación, perseverase categórico en que era Wall "solo quien destruía el misterio con su propia conducta mostrando por ella que deseaba ser conocido para que se hablase de él y de la comisión con que había venido aquím ${ }^{\prime 65}$.

La intención inglesa al revelar el asunto era evidente: crear desavenencias internas entre Francia y España y el resto de sus aliados, haciéndoles pensar en que España pudiera abandonarles. Carvajal era consciente de todo ello: "No pueden haber hecho esas gentes paso más torpe que el de avisar a sus alia$\operatorname{dos}^{\prime \prime 6}$. A tal extremo había llegado la situación:

"Me han desesperado aquellos hombres con el avisar a sus gentes y aún Sada escribe que se sabe en Turín que está allá, que lo ha publicado el cónsul inglés con nombre, apellido y grado. Mira si ahí se hubiera callado cómo nos viéramos ahora" ${ }^{\prime \prime}$.

La estratagema inglesa funcionó. Francia había entrado remisa en la tentativa de Carvajal y, de hecho, sospechaba que Wall tenía poderes, como así era, para cerrar un acuerdo que excluyese los contenciosos galos ${ }^{68}$. Su suspicacia es evidente en las palabras que Huéscar cruzó con Puyzieulx:

"La negociación de Lemán, la cuento por acabada, porque ni nosotros querremos separarnos de franceses con neutralidad absoluta, ni ingleses querrán componerse con nosotros por las condiciones que los proponemos. Pero siempre salimos con la ventaja de saber sus intenciones y si haces memoria de la incertidumbre en que estábamos antes de la misión de Lemán, me confesarás que tengo razón (...)

Puyzieulx me preguntó de oficio sobre lo que hacía Lemán. Busquéle y le hablé en el tono que verás: y preguntándole qué era lo que sabía, me informó casi el todo de su negociación, de modo que o han descubierto la cifra, aunque lo dificulto, o la corte de Viena ha revelado la confianza de los ingleses, como siempre temimos" ${ }^{\prime \prime 9}$.

65. Tabuérniga a Carvajal, 6 de abril de 1748, A.G.S., Estado, 6.913.

66. Carvajal a Wall, 24 de noviembre de 1747, A.G.S., Estado, 6.913.

67. Carvajal a Huéscar, 24 de noviembre de 1747, OZANAM, D., La Diplomacia..., p. 252.

68. El ministro francés se alarma ante la posibilidad de que España acabe firmando unilateralmente la paz: Puyzieulx a Vauréal, 16 de enero de 1748, A.E. Paris, Correspondance politique, Espagne, 497, f. 95. De hecho llega a espetarle a Masones que "eso (la estancia de Wall) tendría traza de una separación con la Francia (en la negociación)", Masones a Huéscar, 16 de febrero de 1748, Archivo de la Casa de Alba (A. Alba), c. 276. Todo ello citado en OZANAM, D., La Diplomacia..., p. 34-35. Huéscar cree que esa desconfianza ha sido conscientemente alimentada desde Viena: "Quizás esto dimana de algún aviso de la Corte de Viena comunicado tal vez a este fin con artificio de resulta de haber la Inglaterra dado cuenta a sus aliados de la misma negociación", Huéscar a Wall, 7 de enero de 1748, A.H.N., Estado, 4.264.

69. Huéscar a Carvajal, 10 de enero de 1748, OZANAM, D., La Diplomacia..., pp. 271-272. 
Así pues el ministerio francés decidió espiar a Wall en Londres: "Aunque no me atreveré a asegurarlo, me inclino a que enviaron de ahí a Londres a espiar a Wall y que ya han retirado su emisario secreto". Llevaba razón; según una carta del rey de Prusia, el espía era el abate Aunillon, antiguo ministro de Francia en Colonia $^{70}$. Se daba pues la paradoja de que tanto Inglaterra como Francia desconfiaban del irlandés. Masones se lo indicaba a Huéscar: tanto Sandwich como Saint-Séverin, los negociadores inglés y francés enviados a Aquisgrán respectivamente, habían acusado, aunque por motivos diferentes, de parcialidad a Wall ${ }^{71}$.

A pesar de la treta británica, Carvajal y España difícilmente podían separarse de la alianza francesa, menos frente a las negativas inglesas a negociar arreglos particulares sin el conocimiento ni el consentimiento de sus aliados. La tentativa de Carvajal chocaba frontalmente con la propia actitud del gabinete británico, que en realidad era poco propicia a la entente.

Todos los intentos de Wall acabaron en fracaso. Durante los primeros días mantuvo una serie de entrevistas con todos los ministros ingleses, Newcastle, Pelham, Harrington y Chesterfield, obteniendo de ellos una respuesta unánime: el rechazo a negociar puntos básicos para Carvajal, como la posibilidad de la restitución de Gibraltar ${ }^{72}$. En octubre elaboró una Memoria que fue respondida en noviembre en similares términos ${ }^{73}$. Todavía Carvajal ordenaría un último esfuerzo, limitado esta vez a los contenciosos hispano-ingleses -los temores de Francia se confirmaban-:

"Me manda el Rey decir a V.S., que proponga una paz particular entre esta y esa corona, limitada a las solas diferencias que han motivado la guerra (...) quedando una y otra con los demás empeños pendientes para seguirlos cada uno con sus aliados ${ }^{\prime \prime 7}$.

Pero, a pesar de las vacilaciones iniciales ante la sorprendente propuesta, el gobierno británico acabó por declinarla ${ }^{75}$.

70. Carvajal a Huéscar, 4 de marzo de 1748, OZANAM, D., La Diplomacia..., p. 297 y n. 2.

71. Huéscar tenía una visión particular del porqué de estas acusaciones: “Wall es cosa muy buena y lo será en todas partes. Bien se arguye lo que es en lo que se oponen los ingleses a su mansión en Londres; yo creo que ellos y los franceses sienten que tengamos allí quien nos dé avisos", Huéscar a Carvajal, 4 de septiembre de 1748, OZANAM, D., La Diplomacia..., p. 378.

72. Wall a Huéscar, 29 de septiembre de 1747, A.H.N., Estado, 4.074.

73. Memoria y Respuesta a la misma, 22 de octubre de 1747 y noviembre de 1747, A.H.N., Estado 4.264.

74. Carvajal a Wall, 24 de noviembre de 1747, A.H.N., Estado, 4.166.

75. Entre otros posibles motivos de la negativa inglesa a negociar aparece el temor a las reacciones de la opinión pública o de la oposición del parlamento y las campañas victoriosas de Francia en Flandes, que hacía más proclive a aquel ministerio a una negociación general: DONOSO NUÑEZ, G., Embajada de Ricardo Wall en Londres. Estudio de las relaciones anglohispánicas entre 1747 y 1754 . Madrid, Tesis doctoral inédita de la U.C.M. leída el 13 de junio de 1964, pp. 90-91. 
En Madrid por si fuera poco, la evolución de estos acontecimientos tenía repercusiones. Tras el éxito político de Carvajal en 1747, su "cofradía" comenzaba a encontrar oposición en un grupo cortesano que se concentraba en torno a Ensenada. La embajada en Londres era uno de los puestos más codiciados por algunas de estas hechuras, y la campaña de desprestigio de Wall así como el fracaso de su misión hacía pensar en un pronto relevo:

"Yo que estoy experimentando su manejo, de que nadie en el mundo podría exceder ni en entendimiento ni en maña y que concibo que algunos buenos efectos que experimentamos vienen de que él está, que aunque fuera en arbitrio mío sustituirle, no hallara cosa no digo igual pero ni bastante, y fuera de eso sé quién lo desea y que tiene el apoyo de la omnipotencia de este polo, y bien ves tú qué comparación cabe entre ambos" ${ }^{\prime 76}$.

La continuidad de Wall en Londres parecía por tanto complicada. El propio Wall, consciente de su fracaso se lo indicaba arteramente a Tabuérniga, haciéndole abrigar falsas esperanzas: "(...) te confesaré ingenuamente deseo partir pues el poco suceso que he tenido en esta nueva carrera me aumenta el anhelo de restituirme a mi primera"77. Ya en mayo, juzgando que su calidad de irlandés le hacía sospechoso, había sugerido a Wall que fuese reemplazado ${ }^{78}$. Pero la respuesta de Carvajal había sido tajante: "No piense V.S. si no es en proseguir ahí por ahora, que es lo que conviene al servicio del Rey"179.

¿A qué se debía la prolongación de su estancia una vez fracasado el encargo principal? El propio Newcastle, a pesar de haberse negado a llegar a un acuerdo con él, le había pedido que se quedase:

“(...) el motivo a mi parecer es que siendo público que yo estoy aquí, la gente quede esperanzada de la paz que desean (...) También con todos los esfuerzos que hacen para juntar un ejército superior temen que la Francia se adelante y dé algún golpe, en cuyo caso se alegrarían de que yo estuviese a la mano para concluir algo" ${ }^{\prime \prime 0}$.

Pero una vez más será sobre todo la fe ciega de Carvajal la que le mantendrá en el puesto. Convencido de sus aptitudes -"corresponde a todo lo que te he oído. Lo hace admirablemente, buenas salidas y discursos" o "en buena hora pensamos enviarle allá. ¡Ojalá hubiera sido antes!" le decía a Huéscar ${ }^{81}{ }_{-}$, aún veía una cierta utilidad en la estancia de Wall en Londres:

76. Carvajal a Huéscar, 9 de septiembre de 1748, OZANAM, D., La Diplomacia..., pp. 381-382. Quienes "lo desean" podrían ser Salas o Bena, hechuras de "la onmipotencia de este polo", es decir, Ensenada. La cursiva es mía.

77. Wall a Tabuérniga, 9 de febrero de 1748, A.H.N., Estado, 4.264.

78. Wall a Huéscar del 14 de mayo, A.H.N., Estado, 4.092.

79. Carvajal a Wall, 6 de junio de 1748, A.H.N., Estado, 4.061.

80. Wall a Huéscar, 2 de febrero, de 1748, A.H.N., Estado, 4.264.

81. Carvajal a Huéscar, 30 de octubre de 1747 y 2 de octubre de 1748, OZANAM, D., La Diplomacia..., p. 240 y p. 392. 


\begin{abstract}
"Paréceme convenientísimo para todo de Lemán se mantenga allí, como te digo de oficio: y creo que lo será expresárselo a Puyzieulx. Y es cierto que en tiempo de parlamento cuanto ocurra ha de poder descubrir y avisar porque se habla todo, y no dejaría de ser importante que pudiese saber y avisar si se transpiraba algo de la negociación entablada en secreto" ${ }^{\prime 22}$.
\end{abstract}

Informar por tanto de todos los rumores y movimientos en la city, pero también, no menos importante, crear las mismas disensiones entre los aliados británicos que Inglaterra había sembrado entre Francia y España.

\title{
7. La continuidad tras Aquisgrán: Wall embajador
}

La paz acabó ajustándose como en ocasiones anteriores a dos bandas: Londres y París. Si el empeño de Carvajal fue ambicioso, los intereses de las dos grandes potencias resultaron insalvables. Las conversaciones de Aquisgrán, un congreso general inaugurado paralelamente a la misión de Wall, fueron el escenario propicio para el acuerdo. Un acuerdo que marginó los intereses de las potencias aliadas a cada una de las dos hegemónicas. Masones de Lima, el enviado español, apenas pudo sino firmar unos artículos en cuya discusión o redacción no había colaborado.

Así pues una nueva paz inestable perpetuaba la situación de equilibrio precario en Europa. Sin embargo, aunque conseguida de un modo poco honroso para España y en unas condiciones mediocres, le proporcionó la oportunidad para el cambio que tanto anhelaba Fernando VI. Por un lado el honor de las armas hispanas quedaba intacto al conseguirse el humilde establecimiento del infante D. Felipe en Parma, Plasencia y Guastalla. Por otro permitía inaugurar un periodo de neutralidad política que en nada semejaba a la constante beligerancia que le había antecedido y que le sucedería.

En este marco optimista, bautizado por algunos historiadores como el "espíritu del $49^{\prime \prime 83}$, se produjo la remodelación definitiva de la diplomacia española, que ya se había iniciado en 1747, pero que sería completada por su ideólogo el ministro de Estado, D. José de Carvajal. Como instrumento fundamental de su política de neutralidad que debía ser, el extremeño no había dudado en rodearse de hechuras fieles, pero también capaces, sobre todo en las embajadas más importantes del continente. Wall y Masones habían sido los ejemplos paradigmáticos, pero quedaban muchas vacantes por cubrir: París (de donde saldría Huéscar en 1749), Viena, Turín...

Sin embargo las aptitudes necesarias para el oficio, los gastos que se derivaban de él y lo ingrato de la vida fuera de la patria reducían enormemente al grupo de candidatos susceptibles de elección. Carvajal se quejaba amargamente de

82. Carvajal a Huéscar, 1 de febrero de 1748. OZANAM, D., La Diplomacia..., p. 280.

83. GOMEZ URDAÑEZ, J. L., El proyecto reformista de Ensenada. Lérida, 1996, p. 89. 
este hecho afirmando que "la tienda no está muy proveída de mercaderías" ${ }^{84}$. Y aunque lo estuviese, eran muchos los intereses en la corte y no necesariamente tenían que coincidir con los del ministro: "Apenas hay de quien echar mano y si se quiere probar uno de esfera, lo estorban. ¿Cómo los ha de haber?"85.

Esta escasez, unida a la confianza de Carvajal, favorecieron a D. Ricardo Wall a la hora de mantenerse al frente de la delegación diplomática hispana en Londres $^{86}$. Sin embargo no eran pocos los contrarios a tal decisión. Por ejemplo el mismo Ensenada:

"Nuestro Wall me ha escrito una carta como suya y como que es para sujeto que le quiere de veras. Toca varios asuntos (...) diré sobre los personales que le parece poco el sueldo y ayuda de costa que se le ha señalado (...) Que está en un país que no es de su gusto, ni él de él, cuya confesión no sabe bien Wall cuánto más concepto le da para mí, pues en lo de irlandés siempre tropecé, porque desconfianza siempre la habrá y aunque no es forastero de marina, acuérdome que preguntando yo a Patiño qué hombre era Montijo y cómo le iba con él, me respondió que activo y de buen deseo, pero muy confuso, añadiendo que en Londres era más útil un basto marinero que supiese la navegación de América y el anexo modo de hacer el comercio ilícito, que el embajador político más hábil del mundo. Wall en todas partes es muy útil, y así lo cree el Rey; pero en mi dictamen lo sería más en Viena, y en Londres un marino" ${ }^{87}$.

Hasta el propio Huéscar tenía algunas dudas, consciente de los sentimientos que había herido el envío de un irlandés descendiente de jacobitas:

"Wall en Londres puede ser bueno o malo. Presto veremos si Newcastle cede en la oposición que le tiene. Si cede éste, ninguno mejor que Wall. Si no cede, será preciso mudarle porque obrará contra viento y mar" ${ }^{\prime 88}$.

Pero Carvajal sabía de sobra qué se había escondido detrás de los rumores que había corrido acerca de la lealtad y la capacidad de Wall. Así se lo comunicaba al duque en respuesta a sus reticencias:

84. Carvajal a Huéscar, 14 de enero de 1747, OZANAM, D., La Diplomacia..., p. 124.

85. Carvajal a Huéscar, 13 de diciembre de 1748, OZANAM, D., La Diplomacia..., p. 417.

86. "No creo haya cosa mejor en el mundo para Londres que Wall y así tiro a dejarle alli", Carvajal a Huéscar, 1 de noviembre de 1748, OZANAM, D., La Diplomacia..., p. 401.

87. Minuta autógrafa de Ensenada, sin indicación de persona a quien fue dirigida (presumiblemente a Carvajal, 8 de abril de 1749, RODRIGUEZ VILLA, A., D. Zenón de Somodevilla, marqués de la Ensenada. Ensayo biográfico. Madrid, 1878, pp. 186-187.

88. Huéscar a Carvajal, 12 de noviembre de 1748, OZANAM, D., La Diplomacia..., p. 406.

89. Carvajal a Huéscar, 25 de noviembre de 1748, OZANAM, D., La Diplomacia..., p. 410. En nota añade Ozanam: "Tabuérniga deseando ser el instrumento de la reconciliación entre España e Inglaterra, no había dejado de maniobrar contra Wall, tratando de desacreditarlo tanto en Londres como en Madrid". 
"Newcastle no ha dejado jamás de agasajar a Wall. Lo que suena en contrario son especies que suelta Tabuérniga que es muy perjudicial allí, iy quiera Dios que aquí no lo sea! Wall conviene allí sin duda" ${ }^{89}$.

Y las habilidades de Wall comenzaban a imponerse poco a poco, captándole un beneplácito que se le había resistido durante meses:

"Ya va su panza de oveja a Wall y te añado que Keene le alaba infinito. Yo le toqué que creía se hallarían bien con él y me dijo que fue aquí grande amigo suyo y con trato continuo largas temporadas. Allá ves cómo le tratan, conque estamos fuera de ese cuidado y queda allí un útil ministro (¡así lo quedara ahí!) y de veras que no sobra nada" ${ }^{\prime \prime 0}$.

Pronto podría jactarse de sus excelentes relaciones con el ministerio inglés, para envidia de los franceses:

“(...) les merezco una grandísima confianza en todos los asuntos: procede de creerme de contragenio de los franceses (...) Bien me persuado de la inquietud del marqués de Puyzieulx. El embajador que está aquí no toca pelota, pero no deja ni por esto de aumentar los celos en que está por mi mucha introducción" ${ }^{\prime \prime 1}$.

Para estas fechas Wall había completado la maniobra definitiva que le había permitido adquirir esa "mucha introducción": la repatriación de Tabuérniga. Con notable moderación y calculada sangre fría, Wall fue elaborando sucesivos informes positivos acerca de la conducta del marqués, aún a sabiendas de sus maquinaciones. Aunque siempre dejaba muy claro que no se fiaba de él, lo presentaba como "muy buen vasallo del Rey S. M. y muy afecto a la real perso$\mathrm{na}^{\prime \prime 92}$. El perdón de Fernando $\mathrm{VI}$, que le permitiese volver del exilio, era la salida más decorosa a una situación insostenible. Wall insistió hasta que logró de Carvajal y del rey la concesión del permiso:

"Se envía la licencia, como verás, a Tabuérniga, que ya no parece que hay motivo de dilatársela y hace fuerza lo que dice Wall que puede embarazar allí a cualquiera, Hábil es, pero caviloso demasiado. Si ahí lo creen misterio, tanto que mejor" ${ }^{\prime \prime 3}$.

El interesado abandonó Londres el 28 de noviembre y, vía Portsmouth y Lisboa, llegó a Madrid el 3 de abril de 1749. No parece casualidad que el cambio de fortuna de Wall en Londres coincida con su salida del país. La suya, por el contrario, seguiría resistiéndose. En Lisboa todavía mantenía fuerzas para pedir a Carvajal la embajada en Turín:

90. Carvajal a Huéscar, 7 de marzo de 1749, OZANAM, D., La Diplomacia..., p. 448.

91. Wall a Ensenada, 13 de agosto de 1749, A.H.N., Estado, 4.277-1.

92. Wall a Carvajal, 28 de noviembre de 1747, A.H.N., Estado, 4.264.

93. Carvajal a Huéscar, 18 de agosto de 1748, OZANAM, D., La Diplomacia..., p. 374. 
"No le cubrirá pelo, yo te lo aseguro, y en mi sentir algo decente y que suene se le debe dar, donde su ligereza y reconocimiento precisamente adquirido a los beneficios de ingleses no puedan hacer daño ni ponerle a él en los apuros de corresponderles mal. Yo le persuadí a la moderación porque la carta que me escribió de Lisboa pidiendo la embajada de Turín como necesario para ella, me daba motivo a ello. No ha nombrado a Wall"94.

Desde luego, el ministro era partidario de encargos más modestos y menos peligrosos:

"Yo he soltado que a Tabuérniga le den un gobierno militar de una plaza porque su cabeza es fatal y si está aquí se procurarán servir de él los ingleses y él enredará mucho. Sus malas influencias hacia Wall espero que las vencerá su sagacidad y buen modo presto" ${ }^{\prime 95}$.

Ni siquiera eso le esperaba al esforzado marqués. Tras mucho batallar consiguió que Fernando VI le reconociese y concediese la pensión que recibía en Londres de Jorge II. Pero sus aspiraciones políticas no pasaron de eso. Murió en 1753. Un año después le seguía Carvajal. Por su parte, debido al fallecimiento de su amigo y tras más de cuatro años como representante español en Londres, Wall daba el salto al ministerio al sustituirle al frente de la Secretaría de Estado. A pesar del fracaso, la misión secreta en Londres había supuesto su cambio de carrera y el inicio de una nueva fulgurante, la política, y había sentado las bases de su ascenso a la cumbre de la administración borbónica.

94. Carvajal a Huéscar, 8 de abril de 1749, OZANAM, D., La Diplomacia..., pp. 457-458.

95. Carvajal a Huéscar, 8 de enero de 1749, OZANAM, D., La Diplomacia..., p. 427. En su respuesta del 17 de enero Huéscar añade que "bueno sería que Tabuérniga tuviese un gobierno para alejarle del oído de Keene", p. 431. 